\title{
Moisture susceptibility assessment of hydrated lime modified asphalt mixture and surface energy
}

\author{
Syed Bilal Ahmed Zaidi (1), Gordon D. Airey ${ }^{(2)}$, James Grenfell ${ }^{(3)}$, Rami M. Alfaqawi ${ }^{(2)}$, Imtiaz \\ Ahmed $^{(2)}$, and Naveed Ahmad ${ }^{(1)}$ \\ (1) Taxila Institute of Transportation Engineering, University of Engineering and Technology, \\ Taxila \\ (2) Nottingham Transportation Engineering Centre, University of Nottingham, Nottingham, UK \\ (3) ARRB, Australian Roads Research Board, VIC, Australia
}

\begin{abstract}
The influence of hydrated lime on moisture susceptibility of asphalt mixture was assessed using a combination of surface energy measurements and modified saturation ageing and tensile stiffness (SATS) test. Four aggregate types, which are commonly used for manufacturing asphalt mixtures in the UK have been selected with 40/60 penetration grade bitumen. These aggregates were from various rocks across the UK which includes felsic intrusive, calcite sedimentary, mafic extrusive and argillaceous sandstone rock sources. Two out of four aggregate sources including felsic intrusive, and argillaceous sandstone showed improvement with the hydrated lime replacement considering results from both surface free energy measurements and modified SATS test, but the performance of aggregates from calcite sedimentary, mafic extrusive rocks remained unaffected. Mineralogical testing of the aggregates, using MLA, showed considerable differences between four aggregate types used in this study. Minerals such as albite, epidote, quartz and chlorite were found predominate in aggregates from felsic intrusive, and argillaceous sandstone sources. Aggregates from calcite sedimentary rock were found abundant in calcite mineral while Argillaceous sandstone aggregates were found rich in chlorite and albite. The difference in the behaviour of four aggregate types to the HL replacement can be credited in part to mineralogical composition of different aggregates. The hydrated lime content of $1 \%$ was observed better than $2 \%$ in the aggregates who showed improved performance with the use of HL. The trends obtained in the surface energy measurements have been found similar to SATS technique. The results clearly
\end{abstract}


illustrate a close agreement between both techniques used in this study for the evaluation of moisture susceptibility. A comparison between ITSM and ITS test after SATS conditioning was also undertaken as some researchers believe that ITS being destructive in nature gives more distinctive results. But the results of ITSM and ITS very found very similar to each other after SATS conditioning in terms of retained strength or retained stiffness.

Keywords: Asphalt mixture, moisture susceptibility, hydrated lime, aggregate mineralogy, surface energy, SATS test.

\section{Introduction}

Hydrated lime (HL) has been used as an additive in asphalt concrete for a number of years (Kennedy 1984; Lesuesur 2010) starting in the 1970s in the United States due to a decline in bitumen quality due to the petroleum crises in 1973. At that time failures due to moisture and frost damage were among the most pressing failure types in road pavements. Various efforts were made to tackle this issue and HL was found to be the most effective solution to challenge these damages (Hicks 1991). As a result of this strong performance, HL was reported to be used in $10 \%$ of the asphalt mixtures produced in the US (Hicks and Scholz 2003).

Extensive research on the use of HL has been carried out over the last 40 years in the US and its use is now not simply limited to being an additive against moisture damage (Lesuesur 2010; Little and Petersen 2005). HL has proved to be a multifunctional additive which improves functional related properties of asphalt mixtures. It is considered as an active filler which improves moisture damage resistance, reduces chemical ageing in bitumen, and stiffens the mastic more than a normal mineral filler, while having no negative effect on resistance to thermal cracking (Lesuesur 2010; Little and Petersen 2005; Sebaaly et al. 2006).

The beneficial effects of HL addition have also been reported in the other parts of the world especially in Europe although research in this area is not as well developed in comparison to the US (Lesuesur 2010). For example, a 20-25\% increment in the durability of the pavement has been recorded by the French northern motorway company with the use of HL in asphalt mixtures (Raynaud 2009). Similarly, in the Netherlands, about $70 \%$ of the highways consist of porous asphalt containing HL (Voskuilen and Verhoef 2003). 
In the UK, the use of HL in asphalt mixtures only began in the early 2000s (Caro et al. 2008) and there is a huge need for further research in this area. In one of the studies on asphalt mixture undertaken by Airey et al. (2008), there was a significant improvement recorded with the addition of HL for acidic aggregate asphalt mixtures. However, further studies are needed to provide a comprehensive understanding of the performance of different aggregate types commonly used in UK.

Although studies have reported improvements in various asphalt mixture performance properties, the main benefits of HL are still primarily linked to improved moisture damage performance of asphalt mixtures. The moisture damage assessment in most of the past studies are based on the results of mechanical testing on asphalt mixtures, (Airey et al. 2008; Kim et al. 2008) without considering any change in physico-chemical properties with the addition of HL. The adhesive properties of the two materials (binder and aggregate in this case) are directly related to their physico-chemical properties especially under moisture susceptible conditions (Manual Series No. 24, 2007). Surface energy properties of the two materials are believed to represent these physico-chemical properties and have been reported as a successful tool for the identification of moisture-resistant materials (Cheng et al. 2002a; Bhasin 2007).

This paper describes the behaviour of HL modified asphalt mixtures with aggregates from various sources and mineralogy found in the UK under moisture susceptible conditions. Moisture susceptibility has been studied using a combination of surface free energy (SFE) techniques and the saturation ageing tensile stiffness (SATS) procedure (Collop et al. 2004)(Grenfell et al. 2012). Although previous studies have investigated the effect of HL on moisture damage performance of asphalt mixture considering surface free energy parameters (Hesami et al. 2013; Nejad et al. 2013), they have been limited. The reason for this is that the theories related to surface energy for asphalt mixture moisture susceptibility cannot always explicitely consider the complex nature of asphaltic materials due to the fact that their bulk chemistry can be significantly different than the SFE properties of the individual constituents (binder and aggregate) (Kim, 2009). For a complete material characterization under a moisture susceptible environment, it is important that a comparison is made between the results of surface energy measurements and those obtained from mechanical testing of the asphalt mixtures. The research paper therefore correlates the results from SATS along with SFE techniques for four aggregate types used in the production of different asphalt mixtures. A comparative analysis has been made between the combinations having HL to the ones without 
HL to see how the surface energy-based predictions compare with conventional moisture damage test methods.

\section{Modified Saturation Ageing Tensile Stiffness (SATS) test}

The saturation ageing tensile stiffness (SATS) procedure was developed to study the moisture damage in the asphalt mixtures (Collop et al. 2004). The SATS test was initially only applicable to high modulus materials but later optimised for universal asphalt mixture applications (Grenfell et al. 2012). This modified SATS test protocol was used during this study.

SATS test setup is shown in Figure 1 with the main features consisting of the following:

- SATS test assembly consisting of a pressure vessel large enough to hold five identical asphalt mixture cores having dimensions of $100 \mathrm{~mm}$ diameter and $60 \mathrm{~mm}$ thickness.

- The vessel is capable of controlling both test temperature and pressure.

- The cores are saturated with water before the test and are mounted on a porous tray as shown in Figure $1 \mathrm{~b}$.

- A known quantity of distilled water is poured into the vessel so that the specimen at position P5 remains immersed during the conditioning period.

- The porous tray mounted with five specimens is placed in the vessel and 0.5 MPa pressure is applied at $85^{\circ} \mathrm{C}$ for 24 hours. This is followed by a further 24 hours cooling period afterwhich the vessel is de-pressurised and opened.

- Specimens are removed from the vessel and their saturated surface dried (SSD) mass is measured. 


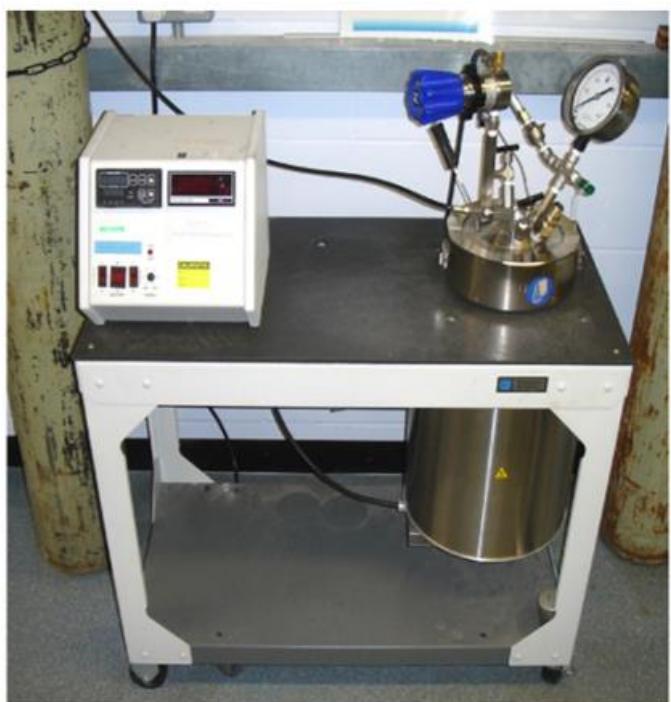

b

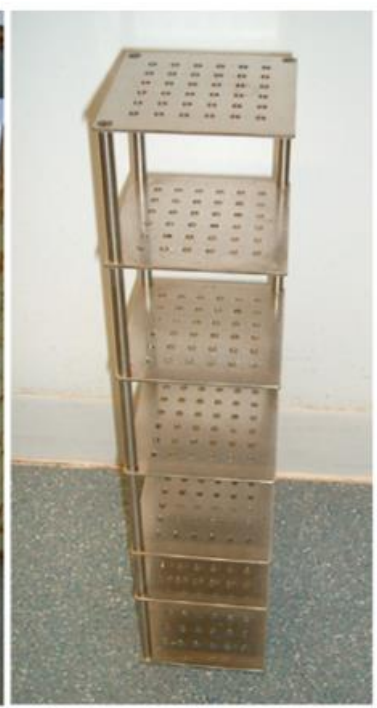

$\mathrm{c}$

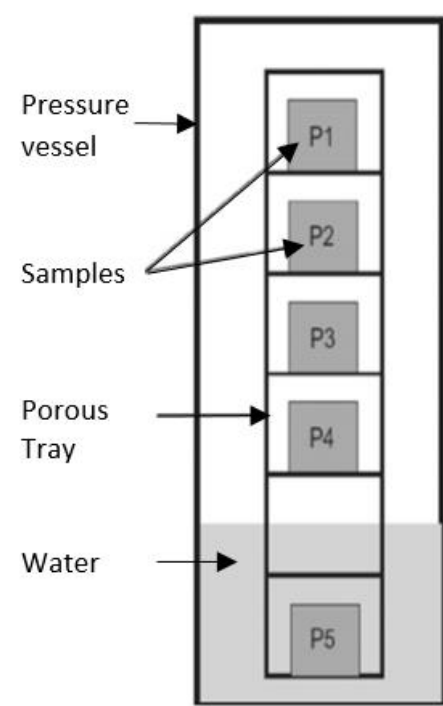

Figure 1: SATS test configuration a) Test Setup b) Porous tray c) inside view of the vessel

A summary of the step by step test procedure is as follows:

- For each test run, the indirect tensile stiffness modulus (ITSM) for five unconditioned test specimens is calculated at $20^{\circ} \mathrm{C}$ in accordance with BS EN 12697-26 (2012) using the Nottingham Asphalt Tester (NAT). This stiffness is recorded as "initial stiffness".

- The dry mass of each specimen is measured after testing for stiffness.

- The five specimens are immersed in distilled water at $20^{\circ} \mathrm{C}$ and are vacuum saturated at $65 \mathrm{kPa}$ for approximately half an hour.

- The wet mass for each specimen is then measured and the initial saturation is calculated in terms of percentage saturation level.

- The SATS vessel is filled with distilled water so that water can be maintained between levels P4 and P5 after loading the specimens into the vessel. Before placing the specimens in the vessel, a temperature of $85^{\circ} \mathrm{C}$ is maintained for about two hours.

- After maintaining the above-mentioned temperature for two hours, specimens positioned on the porous tray are introduced into the vessel and vessel is sealed at the top. The pressure in the vessel is then gradually increased to a value of $0.5 \mathrm{MPa}$.

- Specimens are kept in the vessel at $0.5 \mathrm{MPa}$ pressure and $85^{\circ} \mathrm{C}$ for 24 hours.

- After 24 hours the temperature is decreased to $30^{\circ} \mathrm{C}$ to allow the specimens to cool down for the next 24 hours with the pressure still maintained at $0.5 \mathrm{MPa}$. 
- After the cooling period of 24 hours, the pressure is gradually released. Once at atmospheric pressure, the vessel is opened and the specimens along with tray are removed from the vessel.

- Specimens are surface dried and the SSD determined. Percentage saturation is calculated using SSD weight and referred to as "retained saturation".

- Specimens are conditioned at $20^{\circ} \mathrm{C}$ for at least four hours and are tested for indirect tensile stiffness modulus (ITSM) again. This stiffness after SATS conditioning is referred to as "final stiffness".

- The ratio of initial stiffness to final stiffness is calculated and known as "retained stiffness modulus".

\section{Moisture susceptibility through SFE measurements}

SFE is typically described as a measure of energy or work which is needed for the production of surface area in a vacuum equal to one unit (Good 1966; van Oss et al 1988). The theory of thermodynamics (also known as adsorption theory) can be used for the description of surface free energy of various substrates (solids and liquids) based on their cohesive and adhesive characteristics (Schultz and Nadrin 1994). The values of SFE can be utilized for the calculation of adhesive bond parameters with and without water presence, for different aggregate, filler and binder combinations (Cheng et al. 2002).

\subsection{Binder SFE measurements}

The surface free energy of a liquid or solid cannot be directly measured. For this reason, various indirect methods using different measurement techniques and various solvents, with known SFE values, are used to calculate the SFE of solids and liquids. This study quantifies, the SFE of bitumen and mastics with the Dynamic Contact Analyzer (DCA) by using the Wilhelmy Plate method (Little and Bhasin 2007; Grenfell et al 2014). The surface free energy of binder was determined from contact angles that a binder will produce with three probe liquids in dynamic conditions (Little and Bhasin 2006; Grenfell et al 2014). Glycerol, diiodomethane and water were used as the probe liquids in the study. The probe liquids have been chosen according to given guidelines described by Bhasin (2007) which states that the values of surface free energy of the probe liquid, for measurement of contact angles, should be higher than that of the solid. A low surface energy solvent should not be used for contact angle measurements because 
the solvent will spread over the substrate and accurate contact angle measurements will be very difficult. In addition, the substrate should be examined with at least two polar and one nonpolar solvents. Out of these two polar solvents, one solvent should be basic and the other one should be acidic or have an acid-base characteristic. The surface free energy components of the probe solvents used for binder have been summarized in Table 1.

The procedure for the measurement of surface energy by DCA has been described by Bhasin (2007) and Grenfell et al (2014). In the DCA test, a thin plate $(40 \mathrm{~mm} \times 24 \mathrm{~mm} \times 0.45 \mathrm{~mm})$ which is completely coated with binder is immersed into a probe solvent up to $5 \mathrm{~mm}$ depth and them removed at $40 \mu \mathrm{m} / \mathrm{s}$ constant speed with any changes in the mass of bitumen coated plate during the depth of immersion being recorded (Adamson and Gast 1997). The obtained results are used to measure the contact angle between the binder and at least one probe solvent. Three replicates of each type of binder with a combination of probe solvents were tested at a relative humidity of $50 \pm 5 \%$ and room temperature of $23 \pm 2{ }^{\circ} \mathrm{C}$. An additional sample was used for the confirmation of the thickness of the binder on the coated glass plate using vernier callipers. Results of contact angles obtained from three probe solvents were used in equation 1 . The components of surface energy $\left(\gamma^{L W}, \gamma^{+}\right.$and $\left.\gamma^{-}\right)$were obtained from the solution of equation 1 and further used in equation 2 to get total surface energy.

$$
\begin{gathered}
W_{B L i}=\gamma_{L i}(1+\cos \theta)=2 \sqrt{\gamma_{B}^{L W} \gamma_{L i}^{L W}}+2 \sqrt{\gamma_{B}^{-} \gamma_{L i}^{+}}+2 \sqrt{\gamma_{B}^{+} \gamma_{L i}^{-}} \\
\gamma_{B}^{T}=\gamma_{B}^{L W}+\sqrt[2]{\gamma_{B}^{-} \gamma_{B}^{+}}
\end{gathered}
$$

Where, $W_{B L i}$ is the adhesion bond strength between the binder and probe solvent, $\gamma_{L i}$ is calculated total SFE of the probe solvent and $\theta$ denotes the contact angle between bitumen and probe solvent.

\subsection{Aggregate SFE measurements}

The SFE of high surface energy materials, like aggregates, can be measured with the help of different techniques based on vapour sorption, such as dynamic vapour sorption or the universal sorption technique (Grenfell et al 2014). These vapour sorption techniques are used to calculate the surface energy of aggregate by gas adsorption of selected solvents with known 
surface energy. This method is generally used for aggregates having different shape, size, surface texture and mineralogy.

Oven-dried samples of aggregate passing the $5 \mathrm{~mm}$ sieve size and retained on $2.36 \mathrm{~mm}$ sieve size were used with four probe solvents which include ethyl acetate, octane, chloroform and distilled water. The total surface free energy of the selected probe solvents and their components are summarized in Table 1. During the sorption test, the chosen probe vapours are passed through the aggregate sample under partial vapour pressure and controlled temperature conditions with the help of an inert gas (nitrogen). The selected probe liquids for aggregate testing had comparatively low surface tension as compared to probe liquids that were selected for the bitumen testing in order to achieve a constant adsorption layer of probe vapour on the surface of the aggregate. Because of aggregate surface characteristics, vapours adsorb on the aggregate surface and increase the mass of aggregate that can be measured with a sensitive balance.

Table 1: Surface energy components for the probe liquids used for DVS (units)

\begin{tabular}{|c|c|c|c|c|}
\hline Surface Energy & $\gamma \mathrm{L}$ & $\gamma \mathrm{LLW}$ & $\gamma \mathrm{L}+$ & $\gamma \mathrm{L}-$ \\
\hline Water & 72.8 & 21.8 & 25.5 & 25.5 \\
\hline Glycerol & 64 & 34 & 3.92 & 57.4 \\
\hline Diiodomethane & 50.8 & 50.8 & 0 & 0 \\
\hline Octane & 21.62 & 0 & 0 & 21.62 \\
\hline Ethyl acetate & 23.90 & 0 & 19.20 & 23.90 \\
\hline Chloroform & 27.15 & 3.80 & 0 & 27.15 \\
\hline
\end{tabular}

During the test, the samples of aggregate were exposed to various concentrations of vapour pressure of the probe solvent. Each test was accomplished at a temperature of $25^{\circ} \mathrm{C}$ and the change in the mass of the aggregate due vapour adsorption on the surface of aggregate was uniformly recorded for each increase in the value of vapour pressure to create sorption isotherms. These isotherms were then used for the estimation of specific surface area and dispersion of equilibrium pressure of the aggregate.

The change in aggregate mass due to vapour adsorption was recorded in the chamber of the DVS with the probe vapour over a range of pressures from $0 \%-95 \%$. Changes in the values 
of mass of aggregate-probe solvent combinations were noted with the help of an ultra-sensitive balance with 14 varying partial pressures until an equilibrium partial pressure stage was achieved (Grenfell et al 2014). Equations 3 and 4 were used for the calculation of surface free energy components of aggregate.

$$
\begin{gathered}
W_{A L i}=\pi_{e}+2 \gamma_{L i}=2 \sqrt{\gamma_{B}^{L W} \gamma_{L i}^{L W}}+2 \sqrt{\gamma_{B}^{-} \gamma_{L i}^{+}}+2 \sqrt{\gamma_{B}^{+} \gamma_{L i}^{-}} \\
\gamma_{A}^{T}=\gamma_{A}^{L W}+2 \sqrt{\gamma_{A}^{-} \gamma_{A}^{+}}
\end{gathered}
$$

Where, $W_{A L i}$ is the work of adhesion between aggregate and probe liquid, $\gamma_{L i}$ is the total surface energy of the probe liquid and $\pi_{e}$ represents the spreading pressure of the probe liquid on the aggregate surface.

\subsection{Moisture damage assessment using SFE}

Adhesive or cohesive failure of asphalt mixtures depends on aggregate, bitumen and water surface energy components. The surface energy concept is also used to determine both cohesive as well as adhesive bond strength of asphalt mixtures. Cohesive bond strength can be estimated as twice the total surface energy. Work of adhesion between binder and aggregate is referred to as the adhesive bond strength in dry conditions. Higher values indicate stronger bond between aggregate and binder. The bond strength between aggregate and binder under moisture conditions is termed the work of debonding and a smaller value is desirable as it shows a stronger resistance against moisture-induced damage. If the SEF components of aggregate, binder and water are known, the following two equations (i.e. Equation 5 and Equation 6) can be used for the calculation of work of adhesion and work of debonding.

$$
\begin{gathered}
\Delta G_{B A}^{a}=2 \sqrt{\gamma_{B}^{L W} \gamma_{A}^{L W}}+2 \sqrt{\gamma_{B}^{+} \gamma_{A}^{-}}+2 \sqrt{\gamma_{B}^{-} \gamma_{A}^{+}} \\
\Delta G_{B W A}^{a}=2 \gamma_{W}^{L W}+2 \sqrt{\gamma_{B}^{L W} \gamma_{A}^{L W}}-2 \sqrt{\gamma_{B}^{L W} \gamma_{W}^{L W}}-2 \sqrt{\gamma_{A}^{L W} \gamma_{W}^{L W}} \\
+4 \sqrt{\gamma_{W}^{+} \gamma_{W}^{-}}-2 \sqrt{\gamma_{W}^{+}}\left(\sqrt{\gamma_{B}^{-}}+\sqrt{\gamma_{A}^{-}}\right)-2 \sqrt{\gamma_{W}^{-}}\left(\sqrt{\gamma_{B}^{+}}+\sqrt{\gamma_{A}^{+}}\right) \\
+2 \sqrt{\gamma_{B}^{+} \gamma_{A}^{-}}+2 \sqrt{\gamma_{B}^{-} \gamma_{A}^{+}}
\end{gathered}
$$


Where, $\gamma_{W}^{L W}, \gamma_{W}^{+}$and $\gamma_{W}^{-}$are the SEF components of water (Table 1). Bhasin (2007) has suggested four energy parameters which can also be used for the estimation of moisture damage performance for a given combination of aggregate and binder. These parameters can be determined using Equations 7, 8, 9 and 10.

$$
\begin{aligned}
& E_{1}=\left|\frac{\Delta G_{B A}^{a}}{\Delta G_{B W A}^{a}}\right| \\
& E_{2}=\left|\frac{\Delta G_{B A}^{a}-\Delta G_{B B}^{a}}{\Delta G_{B W A}^{a}}\right| \\
& E_{3}=E_{1} \times S S A \\
& E_{4}=E_{2} \times S S A
\end{aligned}
$$

Where, $\Delta G_{B B}^{a}$ is work of cohesion and SSA is the specific surface area of the aggregate as computed from the DVS test.

The first energy parameter $\left(E_{1}\right)$ assesses the moisture damage performance for two materials (i.e binder and aggregate) considering the work of adhesion and work of debonding. The second parameter $\left(E_{2}\right)$ quantifies moisture sensitivity through binder wettability and work of debonding. While the third and fourth parameters $\left(E_{3}\right.$ and $\left.E_{4}\right)$ include specific surface area (SSA) of aggregates, which gives an insight about aggregate micro-texture. It has been reported by Grenfell et al. (2014) that moisture susceptibility of asphalt mixtures is strongly affected by SSA. The energy parameters three and four can therefore be considered more suitable parameters for the moisture sensitivity assessment.

\section{Material and Asphalt Mixture Variables}

In this paper 40/60 penetration grade neat bitumen has been used with four aggregate types, $\mathrm{A}$, $\mathrm{B}, \mathrm{C}$ and D, having different source and mineralogy. Details of the four aggregate sources along with some basic properties are presented in Table 2 . 
Table 2: Aggregates description and properties

\begin{tabular}{|c|c|c|c|}
\hline $\begin{array}{c}\text { Aggregate } \\
\text { source }\end{array}$ & Description & $\begin{array}{c}\text { Particle density } \\
\left(\mathrm{Mg} / \mathrm{m}^{3}\right)\end{array}$ & $\begin{array}{c}\text { Water absorption } \\
(\%)\end{array}$ \\
\hline A & Felsic intrusive rock & 2.77 & 0.40 \\
\hline B & Calcite sedimentary rock & 2.70 & 1.20 \\
\hline C & Mafic extrusive rock & 2.96 & 2.41 \\
\hline D & $\begin{array}{c}\text { Argillaceous sandstone } \\
\text { rock }\end{array}$ & 2.80 & 0.90 \\
\hline
\end{tabular}

Mineral liberation analysis (MLA) has been used to quantify the mineral composition of the four aggregates used in this study. The results are presented in Table 3 for each aggregate type. MLA analysis identifies mineral composition in any polished drilled core, granular or material lump. The values were obtained with the help of a FEI Quanta 600 SEM with MLA capability to find the mineral phases of the different aggregates (Zhang et al 2015). For preparing MLA samples, aggregates were cast in resin in the first stage and after hardening of the resin, surface polishing was undertaken in stage two. In the third stage, samples were coated with carbon to make them electron conductive followed by scanning in BSE mode with the Electron Dispersive X-ray analysis (EDX) carried out in an array of spots across the particles. The resultant spectra were then used to determine mineral phases at specific points in the microstructure which allowed mineralogical maps to be generated for each aggregate type.

Table 3: Aggregate mineralogical composition (as a percentage) through MLA

\begin{tabular}{|c|c|c|c|c|}
\hline Mineral Name & A & B & C & D \\
\hline Albite & 27.25 & - & 25.13 & 2.91 \\
\hline Epidote-group & 23.03 & - & 9.65 & 0.06 \\
\hline Quartz & 21.31 & - & 5.57 & 67.31 \\
\hline Chlorite & 16.67 & - & 31.66 & 9.08 \\
\hline K-feldspar & 6.01 & - & 5.06 & 8.21 \\
\hline Illite & 3.15 & - & 7.01 & 1.51 \\
\hline Biotite-group & 1.55 & - & 3.31 & 3.60 \\
\hline Titanite & 0.47 & - & 1.25 & 0.32 \\
\hline Calcite & - & 98.82 & 8.10 & 0.61 \\
\hline Pyrite & - & 0.21 & - & - \\
\hline Apatite & - & 0.13 & - & 0.20 \\
\hline
\end{tabular}




\begin{tabular}{|c|c|c|c|c|}
\hline Clay & - & 0.07 & - & 2.19 \\
\hline Muscovite & - & - & - & 1.97 \\
\hline Garnet & - & - & 1.01 & - \\
\hline Others & 0.34 & 0.61 & 2.28 & 2.03 \\
\hline
\end{tabular}

Five fillers have been used which includes four fillers from the four aggregates used in this study and the fifth is hydrated lime (HL). For mixture testing, filler content has been fixed to $5 \%$ throughout this study and three different compositions have been used for each aggregate type. Composition 1 is composed of $0 \% \mathrm{HL}$ with $5 \%$ respective filler depending upon the main aggregate type in the mixture. For example, if the main source is A, composition 1 will be $0 \%$ HL plus 5\% aggregate A filler. The same principle will be used in the cases of Aggregates B, $\mathrm{C}$ and D. On the same lines, composition 2 will consist of $1 \% \mathrm{HL}$ and $4 \%$ of the parent filler. And similarly, composition 3 will be made up of $2 \% \mathrm{HL}$ and $3 \%$ of either aggregates A, B, C or D filler. This means that HL will be used as a replacement for the main filler content and not as an additional filler. The idea behind this methodology is to evaluate the real effect of HL in the mixture because if HL is used as additional filler in the mixture there will be the effect of a change in mixture volumetrics rather than the effect of HL.

The addition of HL to the mixture can be done in three possible ways. (1) dry hydrated lime to the dry aggregate (2) dry hydrated lime to the wet aggregates (3) HL slurry to the aggregates. Many studies show that the method of HL addition to the aggregates does not affect the mixture's moisture sensitivity (McCann and Sebaaly 2006). In this paper, for the mixture level testing, HL has been added as dry HL to the dry aggregates as this is the most convenient method which allows good control of the HL dosage.

Preparation of asphalt mixture was undertaken by using $14 \mathrm{~mm}$ close graded surface course in accordance with BS EN 13108-1 (2016). The gradation curve has been plotted in Figure2 for all four aggregate types used with maximum and minimum limits as per BS 4987-1 (2005). Different variables for mixture level testing are as follows:

- Binder type (one): 40/60 pen

- Binder content (one): $5 \%$ by mass

- Air void content (range): $8-10 \%$ air voids 
- Filler content (one, with three compositions): $5 \%$ by mass

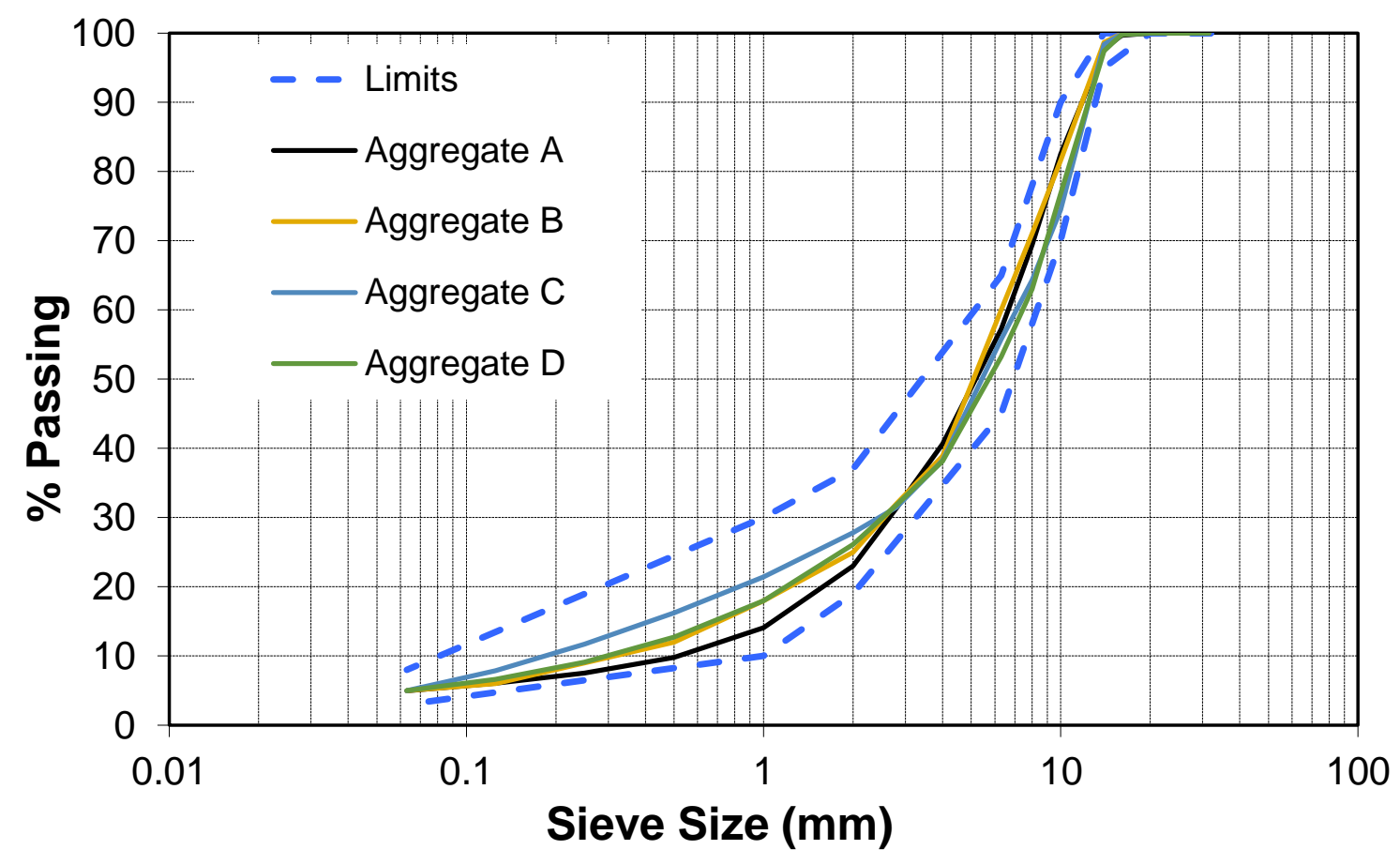

Figure 2: Gradation curve for aggregates A, B, C and D with threshold limits

For the SATS test, a total of 12 combinations have been tested with two runs for each combination. Roller compaction has been used to manufacture the slabs having target air voids between 8 to $10 \%$. From each slab, 5 cores have been trimmed with a $100 \mathrm{~mm}$ diameter and $60 \mathrm{~mm}$ thickness. Only the cores that achieved the target air void of 8-10\% have been used for SATS testing.

For the measurements of surface energy parameters, each individual aggregate source has been tested with four binder types. These binder types include one 40/60 neat bitumen and three mastics. With the four aggregate sources, twelve mastic types have been used in combination. The notation, composition and the aggregate type with which these mastics have been used for the measurements of surface energy parameters, are presented in Table 4.

For mastic preparation, about 300 grams of binder was heated in an oven at $160^{\circ} \mathrm{C}$. The required filler was prepared after that by considering the mastic type. Filler and binder were then mixed simultaneously at $160^{\circ} \mathrm{C}$ by continuous manual stirring (5-10 minutes) to get a homogeneous mixture. To avoid filler settling in the binder, the mastic was continuously stirred 
during cooling until the temperature became low enough to avoid filler settlement. The samples were then stored for testing at a later stage. Before each test, the mastics were heated to a liquid and stirred to ensure homogeneity. To ensure homogeneity in each mastic set, softening point tests were performed and results were compared to each other. The results showed that manual mixing of filler combinations used in this research study was reliable and repeatable.

Table 4: Summary of mastics notation, composition and type of aggregate used in combination

\begin{tabular}{|c|c|c|c|}
\hline $\begin{array}{l}\text { Serial } \\
\text { No. }\end{array}$ & Mastic Notation & Composition & $\begin{array}{l}\text { Used in combination } \\
\text { with Aggregate type }\end{array}$ \\
\hline 1 & $50 \% \mathrm{~A}$ & $\begin{array}{l}50 \% \text { Aggregate A filler }+50 \% \\
40 / 60 \text { pen neat bitumen }\end{array}$ & A \\
\hline 2 & $40 \% \mathrm{~A}+10 \% \mathrm{HL}$ & $\begin{array}{l}40 \% \text { Aggregate A filler }+10 \% \\
\text { Hydrated lime }+50 \% 40 / 60 \text { pen neat } \\
\text { bitumen }\end{array}$ & $\mathrm{A}$ \\
\hline 3 & $30 \% \mathrm{~A}+20 \% \mathrm{HL}$ & $\begin{array}{l}30 \% \text { Aggregate A filler }+20 \% \\
\text { Hydrated lime }+50 \% 40 / 60 \text { pen neat } \\
\text { bitumen }\end{array}$ & A \\
\hline 4 & $50 \% \mathrm{~B}$ & $\begin{array}{l}50 \% \text { Aggregate B filler }+50 \% 40 / 60 \\
\text { pen neat bitumen }\end{array}$ & B \\
\hline 5 & $40 \% \mathrm{~B}+10 \% \mathrm{HL}$ & $\begin{array}{l}40 \% \text { Aggregate B filler }+10 \% \\
\text { Hydrated lime }+50 \% 40 / 60 \text { pen neat } \\
\text { bitumen }\end{array}$ & B \\
\hline 6 & $30 \% \mathrm{~B}+20 \% \mathrm{HL}$ & $\begin{array}{l}30 \% \text { Aggregate B filler }+20 \% \\
\text { Hydrated lime }+50 \% 40 / 60 \text { pen neat } \\
\text { bitumen }\end{array}$ & $\mathrm{B}$ \\
\hline 7 & $50 \% \mathrm{C}$ & $\begin{array}{l}50 \% \text { Aggregate } \mathrm{C} \text { filler }+50 \% 40 / 60 \\
\text { pen neat bitumen }\end{array}$ & $\mathrm{C}$ \\
\hline 8 & $40 \% \mathrm{C}+10 \% \mathrm{HL}$ & $\begin{array}{l}40 \% \text { Aggregate } \mathrm{C} \text { filler }+10 \% \\
\text { Hydrated lime }+50 \% 40 / 60 \text { pen neat } \\
\text { bitumen }\end{array}$ & $\mathrm{C}$ \\
\hline 9 & $30 \% \mathrm{C}+20 \% \mathrm{HL}$ & $\begin{array}{l}30 \% \text { Aggregate } \mathrm{C} \text { filler }+20 \% \\
\text { Hydrated lime }+50 \% 40 / 60 \text { pen neat } \\
\text { bitumen }\end{array}$ & $\mathrm{C}$ \\
\hline 10 & $50 \% \mathrm{D}$ & $\begin{array}{l}50 \% \text { Aggregate } \mathrm{D} \text { filler }+50 \% \\
40 / 60 \text { pen neat bitumen }\end{array}$ & $\mathrm{D}$ \\
\hline 11 & $40 \% \mathrm{D}+10 \% \mathrm{HL}$ & $\begin{array}{l}40 \% \text { Aggregate D filler }+10 \% \\
\text { Hydrated lime }+50 \% 40 / 60 \text { pen neat } \\
\text { bitumen }\end{array}$ & $\mathrm{D}$ \\
\hline 12 & $30 \% \mathrm{D}+20 \% \mathrm{HL}$ & $\begin{array}{l}30 \% \text { Aggregate D filler }+20 \% \\
\text { Hydrated lime }+50 \% 40 / 60 \text { pen neat } \\
\text { bitumen }\end{array}$ & $\mathrm{D}$ \\
\hline
\end{tabular}


To make the results of both SATS and SFE testing comparable, filler to binder (F/B) ratio is kept as 1:1, which agrees with various past studies (Airey et al. 2008; Grenfell et al. 2014; Wang et al. 2011).

\section{Results}

\subsection{Moisture Damage Assessment using Surface Energy}

SFE components of neat bitumen (40/60 pen) and the twelve mastic types have been computed through the Wilhelmy plate method and listed in Table 5. The 40/60 neat bitumen used in this paper is of a typical acidic nature and can be matched with results of other past studies (Kakar et al. 2016; Nejad et al. 2013).

Table 5: Surface free energy components of all bitumen/ mastic samples

\begin{tabular}{|c|c|c|c|c|}
\hline \multirow[t]{2}{*}{ Bitumen/Mastic } & \multicolumn{3}{|c|}{ Surface energy components $\left(\mathrm{mJ} / \mathrm{m}^{2}\right)$} & \multirow{2}{*}{$\begin{array}{l}\text { Total Surface Energy } \\
\gamma\left(\mathrm{mJ} / \mathrm{m}^{2}\right)\end{array}$} \\
\hline & $\gamma^{\mathrm{LW}}$ & $\gamma^{+}$ & $\gamma^{-}$ & \\
\hline $40-60$ Neat & 19.040 & 1.316 & 0.990 & 21.323 \\
\hline $50 \% \mathrm{~A}$ & 23.696 & 0.350 & 1.680 & 25.232 \\
\hline $40 \% \mathrm{~A}+10 \% \mathrm{HL}$ & 28.072 & 0.012 & 2.316 & 28.411 \\
\hline $30 \% \mathrm{~A}+20 \% \mathrm{HL}$ & 28.744 & 0.000 & 8.865 & 28.747 \\
\hline $50 \% \mathrm{~B}$ & 36.609 & 0.147 & 1.490 & 37.544 \\
\hline $40 \% \mathrm{~B}+10 \% \mathrm{HL}$ & 36.665 & 0.177 & 2.028 & 37.865 \\
\hline $30 \% \mathrm{~B}+20 \% \mathrm{HL}$ & 37.990 & 0.095 & 1.209 & 38.669 \\
\hline $50 \% \mathrm{C}$ & 29.764 & 0.0278 & 0.803 & 30.063 \\
\hline $40 \% \mathrm{C}+10 \% \mathrm{HL}$ & 28.955 & 0.112 & 0.296 & 29.320 \\
\hline $30 \% \mathrm{C}+20 \% \mathrm{HL}$ & 29.799 & 0.009 & 1.424 & 30.032 \\
\hline $50 \% \mathrm{D}$ & 29.330 & 0.0004 & 3.787 & 29.407 \\
\hline $40 \% \mathrm{D}+10 \% \mathrm{HL}$ & 31.368 & 0.036 & 6.934 & 32.380 \\
\hline
\end{tabular}




\begin{tabular}{|l|l|l|l|l|}
\hline $30 \% \mathrm{D}+20 \% \mathrm{HL}$ & 29.400 & 0.017 & 7.170 & 30.112 \\
\hline
\end{tabular}

The surface energy of the four aggregates varies considerably among different types and sources. This difference is not only in terms of total energy but also among the components. This difference in the energy can be due to the fact that different aggregates vary considerably in their composition depending on their source and type. This difference has a considerable effect on the adhesive properties when bitumen comes in contact with aggregates in the form of a bituminous mixture. If the components of SFE of aggregate A, which is an acidic natured felsic intrusive rock, are studied, it can be seen that its basic component is more than its acidic component. This can happen as the surface chemistry and bulk chemistry of a material can be different (Kim, 2009). In addition, the results from some other research works show the same type of variation in the acidic and basic components (Ahmad 2011; Liu et al. 2013).

Table 6: Surface free energy components of all aggregate types

\begin{tabular}{|c|l|l|c|l|l|}
\hline \multirow{2}{*}{$\begin{array}{l}\text { Aggregate } \\
\text { Source }\end{array}$} & \multicolumn{2}{|l|}{ Surface energy components $\left(\mathrm{mJ} / \mathrm{m}^{2}\right)$} & $\begin{array}{l}\text { Total surface } \\
\text { energy, } \gamma\left(\mathrm{mJ} / \mathrm{m}^{2}\right)\end{array}$ & $\begin{array}{l}\text { Specific surface } \\
\text { area, } \gamma\left(\mathrm{m}^{2} / \mathrm{g}\right)\end{array}$ \\
\cline { 2 - 6 } & $\gamma^{\mathrm{LW}}$ & \multicolumn{1}{|c|}{$\gamma^{+}$} & $\gamma^{-}$ & & \\
\hline A & 68.97 & 17.41 & 569.68 & 199.18 & 0.3819 \\
\hline B & 65.81 & 0.98 & 375.72 & 104.19 & 0.7173 \\
\hline C & 66.66 & 176.03 & 214.92 & 389.01 & 1.7817 \\
\hline D & 57.00 & 4.46 & 1435.62 & 57.00 & 1.9450 \\
\hline
\end{tabular}

The surface free energies of the bitumen/mastic and aggregates were used to determine the interfacial work of adhesion under dry conditions as well as the work of de-bonding under wet conditions. A summary of the work of adhesion and debonding for all the combinations of bitumen/mastic and aggregates used in this study have been shown in Figure 3.

By looking at the results for aggregate A and comparing the work of adhesion and de-bonding results for mastic having only aggregate A filler to the mastics with 10 or $20 \%$ HL replacement, it can be derived that the work of adhesion has increased by about $9.5 \%$ with the replacement of $10 \% \mathrm{HL}$ and by about $56 \%$ with $20 \%$ HL replacement. Along the same lines, the work of 
de-bonding dropped down $9 \%$ with the replacement of $10 \% \mathrm{HL}$ and dropped massively again by $51 \%$ with $20 \%$ HL replacement.

Work of adhesion

Aggregate $A$

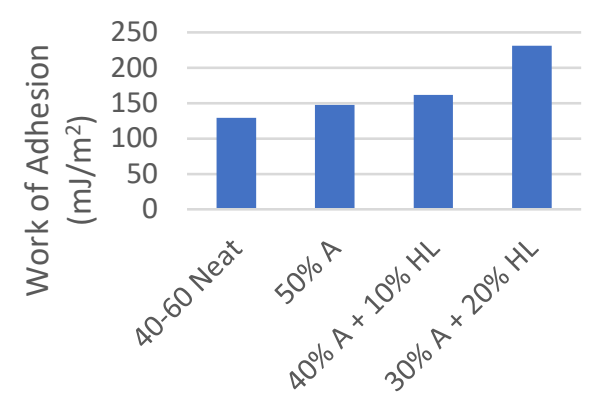

Aggregate B

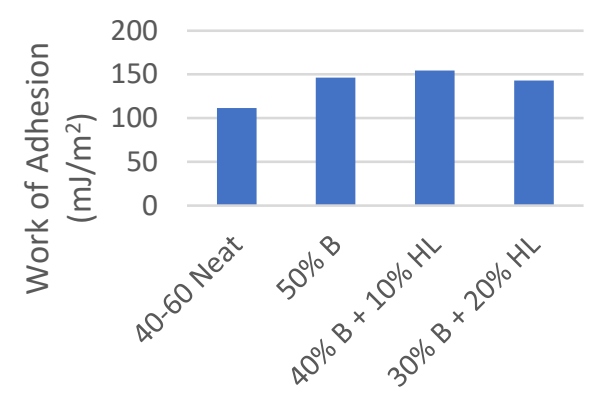

Aggregate C

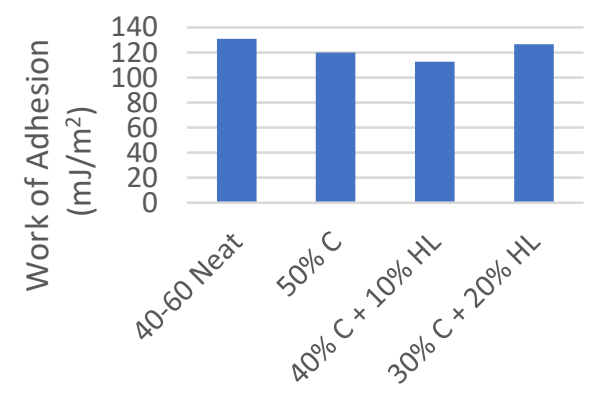

Work of de-bonding

Aggregate $A$

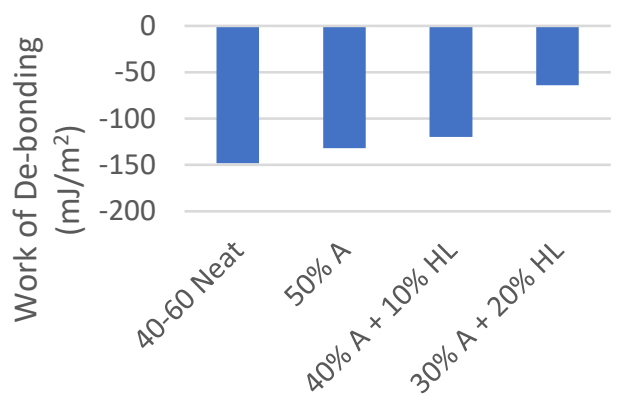

Aggregate $B$

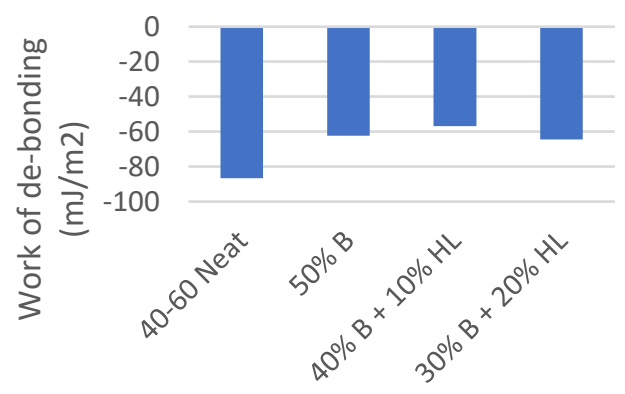

Aggregate C

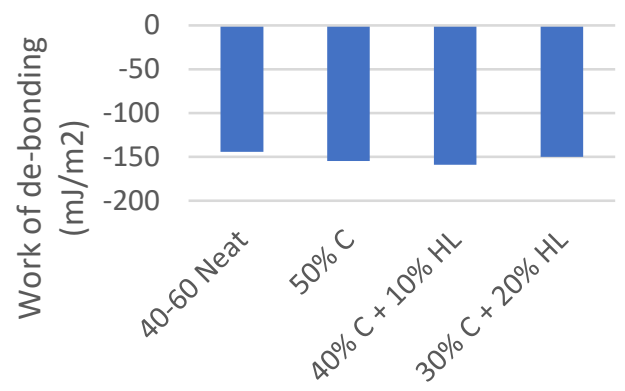


Aggregate D

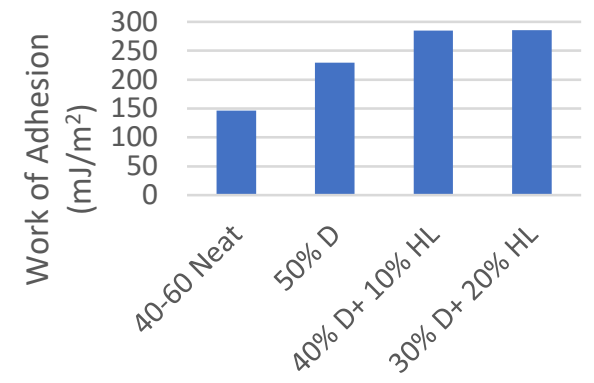

Aggregate D

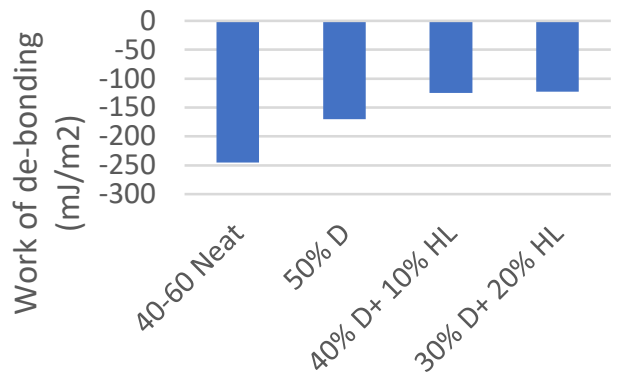

Figure 3: Work of adhesion and work of de-bonding for bitumen/mastics and aggregates combinations

For aggregate B, on the other hand, the replacement of HL in mastics has not shown any positive results both for the work of adhesion and the work of de-bonding. Although there has been some difference noted between neat bitumen and the other mastics, all the combinations of mastics have almost the same work of adhesion and de-bonding values. Aggregate $\mathrm{C}$ also didn't show any positive signs of HL replacement to mastics. The results of all combinations of mastics and even neat bitumen are very similar to each other.

But considering the results of the work of adhesion and de-bonding for aggregate $\mathrm{D}$, there are some interesting findings. This aggregate type has shown positive results with the replacement of the filler with HL. Work of adhesion for the mastics with 10 and 20\% HL has increased by $25 \%$ compared to the mastic with $0 \%$ HL. By analysing the work of de-bonding results a decrease of $26 \%$ and $25 \%$ has been calculated with the replacement of $10 \%$ and $20 \% \mathrm{HL}$ respectively.

For the assessment of moisture damage performance and separating good and poor performing binder-aggregate combinations, Little and Bhasin (2006) and Bhasin (2007) recommended a set of threshold values for fthe our energy parameter discussed above. These values are 0.75 , $0.50,0.50$ and 0.35 for energy parameters $E_{1}, E_{2}, E_{3}$ and $E_{4}$ respectfully. It has been reported in various past studies that these energy parameters have been used for identification of good and poor binder and aggregate blends (Grenfell et al. 2014; Howson et al. 2012; Liu et al. 2013). Furthermore, SSA has been reported to have a big influence on moisture susceptibility of asphalt mixtures. So as far as the performance of a given binder-aggregate combination is concerned, $E_{3}$ and $E_{4}$ can be referred to as more appropriate energy parameters under moisture susceptible environments (Grenfell et al. 2014). Moisture damage performance at mixture level 
can also be predicted through the four energy parameters as some strong correlations exist between theses parameters and results of mechanical moisture damage tests at mixture level (Grenfell et al. 2014; Guo et al. 2014).

Table 7 summarises the values of all the four energy parameters $E_{1}, E_{2}, E_{3}$ and $E_{4}$ for various test combinations. The values presented in Table 7 cannot be interpreted based on the threshold limits suggested by Bhasin (2007) as the suggested limits were for neat bitumen only. For the mastics, these threshold limits can be quantified by conducting a study similar to Bhasin (2007) on the materials under consideration. By looking at the results presented in Table 7 it can be stated that with the addition of HL to the aggregate A combination has resulted in an improvement especially in the mastic having $20 \% \mathrm{HL}$ where there is a more than $200 \%$ improvement in all the four energy parameters.

Table 7: Bond energy parameters, $\mathrm{E}_{1}, \mathrm{E}_{2}, \mathrm{E}_{3}, \mathrm{E}_{4}$ for binder-aggregate combinations

\begin{tabular}{|c|c|c|c|c|}
\hline Description & $\mathbf{E}_{1}$ & $\mathbf{E}_{2}$ & $\mathbf{E}_{3}$ & $\mathbf{E}_{4}$ \\
\hline \multicolumn{5}{|c|}{ Aggregate $\mathrm{A}$} \\
\hline $40-60$ Neat & 0.88 & 0.59 & 0.33 & 0.22 \\
\hline $50 \% \mathrm{~A}$ & 1.12 & 0.74 & 0.43 & 0.28 \\
\hline $40 \% \mathrm{~A}+10 \% \mathrm{HL}$ & 1.35 & 0.88 & 0.52 & 0.33 \\
\hline $30 \% \mathrm{~A}+20 \% \mathrm{HL}$ & 3.61 & 2.71 & 1.38 & 1.03 \\
\hline \multicolumn{5}{|c|}{ Aggregate B } \\
\hline 40-60 Neat & 1.29 & 0.80 & 0.92 & 0.57 \\
\hline $50 \% \mathrm{~B}$ & 2.34 & 1.14 & 1.68 & 0.82 \\
\hline $40 \% \mathrm{~B}+10 \% \mathrm{HL}$ & 2.72 & 1.38 & 1.95 & 0.99 \\
\hline $30 \% \mathrm{~B}+20 \% \mathrm{HL}$ & 2.22 & 1.02 & 1.59 & 0.73 \\
\hline \multicolumn{5}{|c|}{ Aggregate C } \\
\hline 40-60 Neat & 0.91 & 0.61 & 1.62 & 1.09 \\
\hline $50 \% \mathrm{C}$ & 0.77 & 0.39 & 1.38 & 0.69 \\
\hline $40 \% \mathrm{C}+10 \% \mathrm{HL}$ & 0.71 & 0.34 & 1.26 & 0.61 \\
\hline $30 \% \mathrm{C}+20 \% \mathrm{HL}$ & 0.84 & 0.44 & 1.51 & 0.79 \\
\hline \multicolumn{5}{|c|}{ Aggregate D } \\
\hline 40-60 Neat & 0.60 & 0.42 & 1.16 & 0.82 \\
\hline
\end{tabular}




\begin{tabular}{|c|l|l|l|l|}
\cline { 2 - 5 } $50 \% \mathrm{D}$ & 1.35 & 1.00 & 2.62 & 1.95 \\
\hline $40 \% \mathrm{D}+10 \% \mathrm{HL}$ & 2.28 & 1.76 & 4.44 & 3.43 \\
\hline $30 \% \mathrm{D}+20 \% \mathrm{HL}$ & 2.33 & 1.84 & 4.53 & 3.57 \\
\hline
\end{tabular}

For aggregate B combinations, results of all four energy parameters look very similar to one another. In the presence of $10 \% \mathrm{HL}$, there was a slight improvement observed but when $20 \%$ HL was added to the aggregate B combination the results showed a relative decreased performance in comparison to mastics with $0 \% \mathrm{HL}$ and $10 \% \mathrm{HL}$. So, for aggregate B it can be concluded that there is practically no beneficial effect of HL observed from results based on the four energy parameters.

Type $\mathrm{C}$ aggregate has also shown hardly any effect of HL addition with the main difference observed between the results of neat bitumen and mastics but there is hardly any difference between the three mastics. Addition of $20 \%$ HL has shown a slight improvement, but all the results are in a very narrow band.

The results of type D aggregate are interesting as they have shown significant improvement with HL replacement compared to the mastic having only type D filler. The replacement with $10 \%$ HL results in a huge improvement of around $70 \%$ for all the four energy parameters. Replacement of $20 \%$ HL didn't improve the performance any further as the results of the combinations with $10 \% \mathrm{HL}$ and $20 \%$ HL are very similar in terms of energy parameters.

\subsection{SATS Test Results}

SATS test results in terms of retained saturation against retained stiffness have been summarised in Figure 4 for aggregate A. All three combinations have been put together in one figure to make an easy comparison between them and to see if HL has any beneficial effect against moisture damage resistance. By looking carefully at the results for aggregate A it can be seen that although the type A aggregate used in this paper is not of poor quality in terms of field performance, it has shown some improvements in terms of moisture damage performance with the addition of HL. The difference between the mixture with $0 \% \mathrm{HL}$ and 1 or $2 \% \mathrm{HL}$ is not vast but there is definitely some increase in the retained stiffness. This small difference may be due to the fact that aggregate A used in the study is already of good quality and, although HL improves the overall performance, it is only a minor increase. 
Similarly, Figure 5 is a graphical representation of retained saturation against retained stiffness for the three combinations of aggregate B. Again there is some difference observed with the addition of HL in the mixture. In fact, the addition of HL has improved the moisture damage performance of type B aggregate and the best results have been achieved with the addition of $1 \%$ HL.

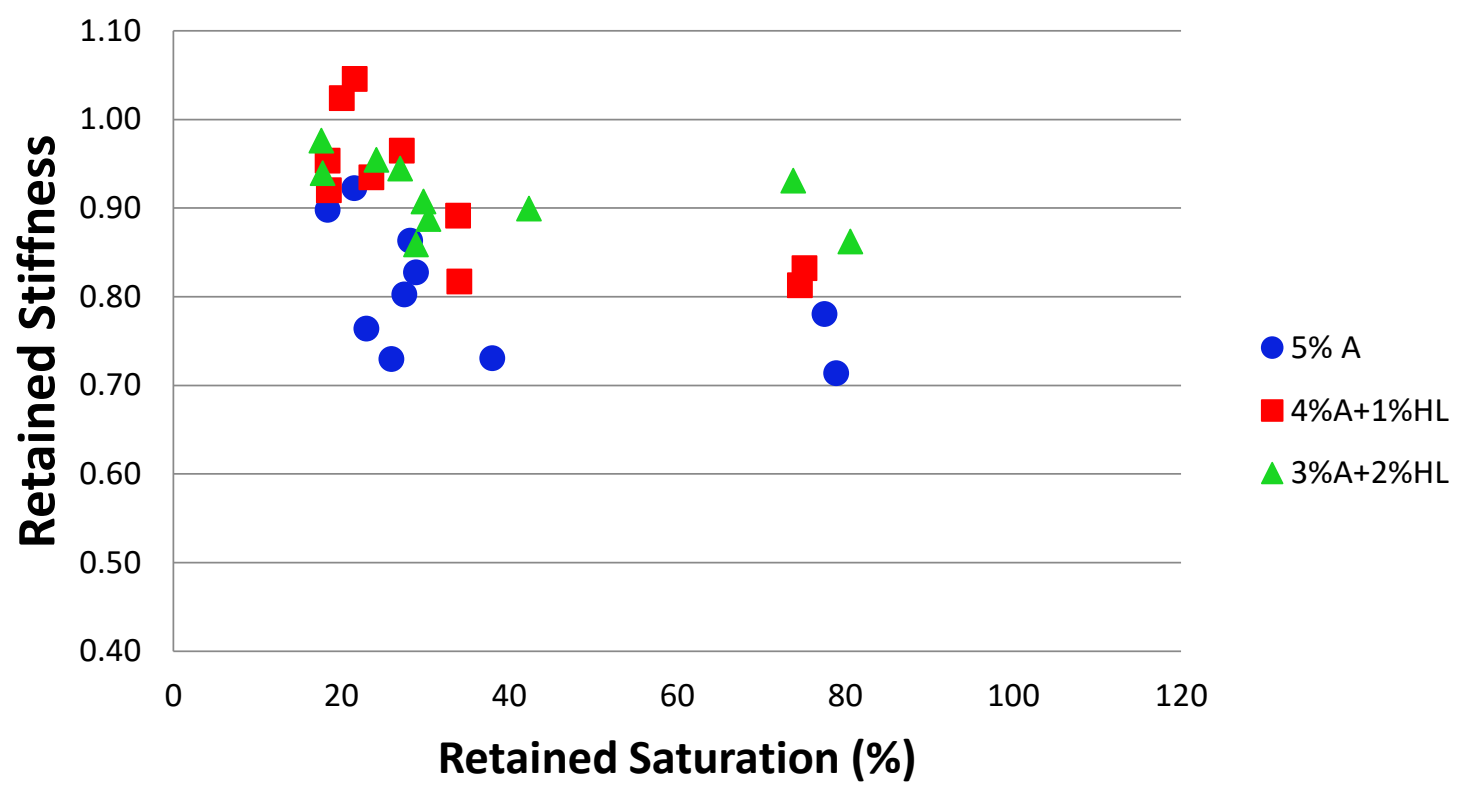

Figure 4: SATS test results for all combinations of aggregate A 


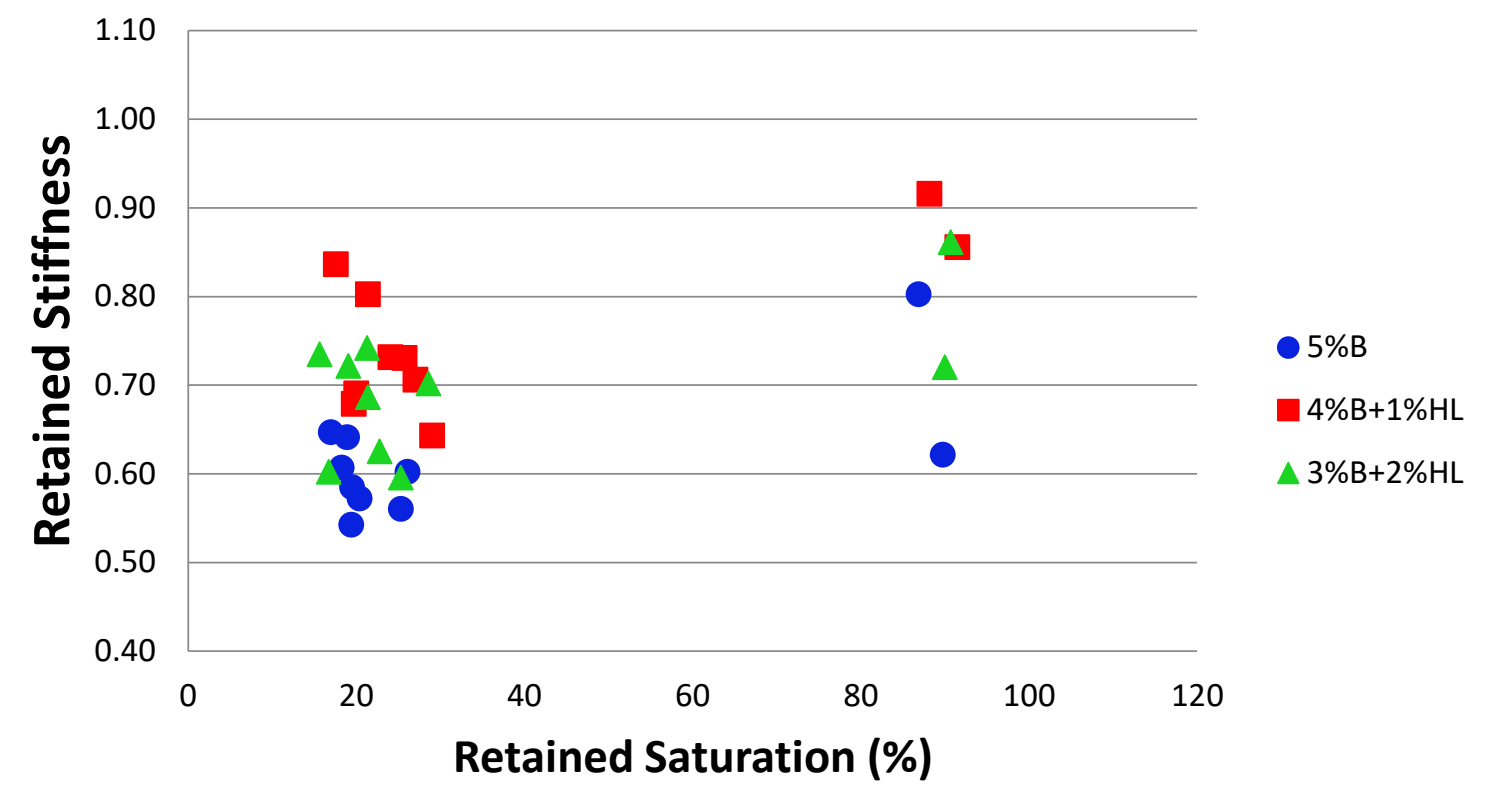

Figure 5: SATS test results for all combinations of aggregate B

The results of aggregate $\mathrm{C}$ are a bit different from type $\mathrm{A}$ and $\mathrm{B}$ aggregates as shown in Figure 6. The addition of HL to type $\mathrm{C}$ aggregate does not seem to make any difference as the results of all the three combinations i.e. $0 \% \mathrm{HL}, 1 \% \mathrm{HL}$ and $2 \% \mathrm{HL}$ are very close to each other. Asphalt mixture made with type $\mathrm{C}$ aggregate seems to have good resistance against moisture damage even without the addition of HL so it can be concluded that HL addition has no beneficial effect if used in combination of aggregate type $\mathrm{C}$. 


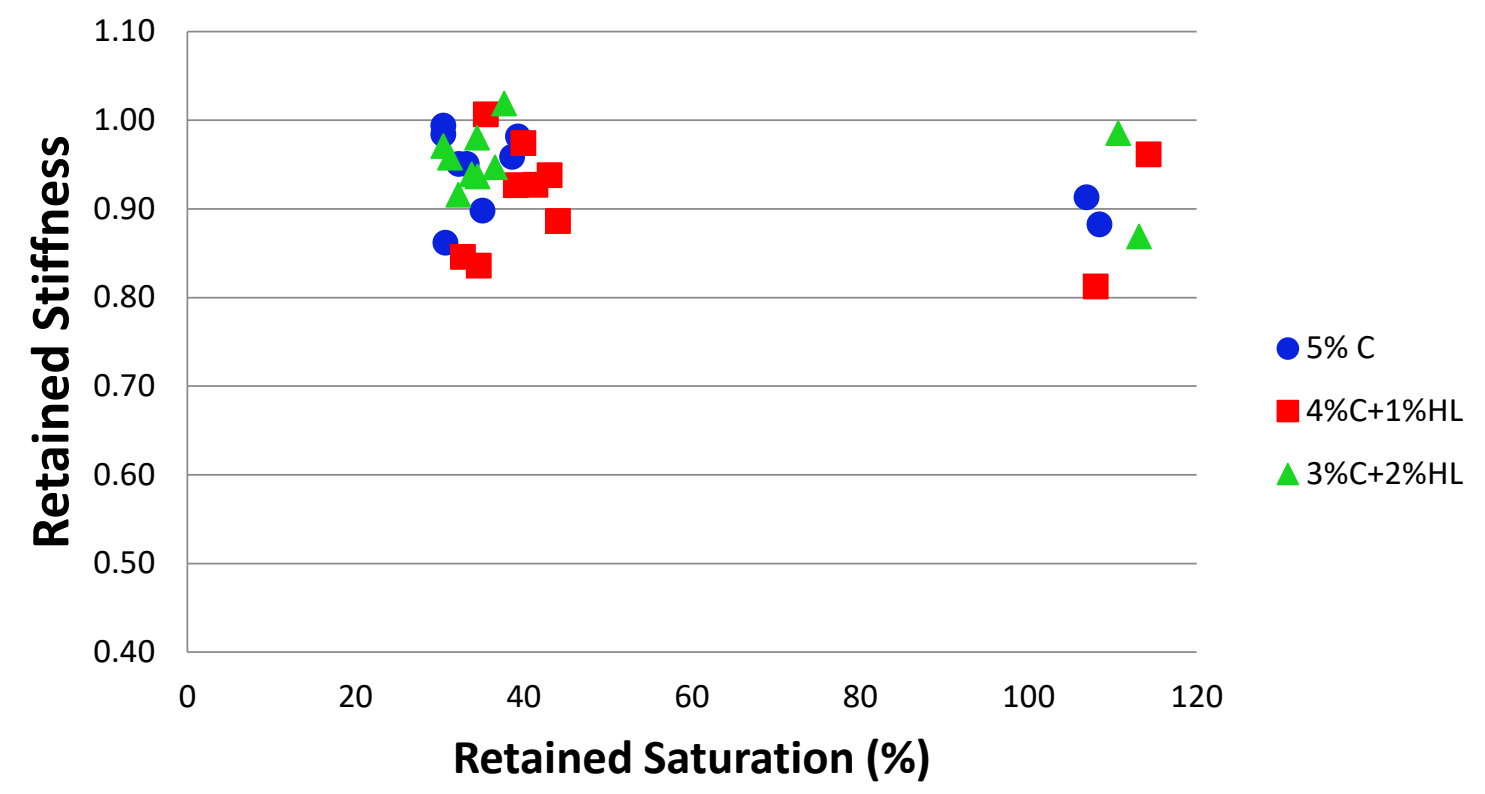

Figure 6: SATS test results for all combinations of aggregate $\mathrm{C}$

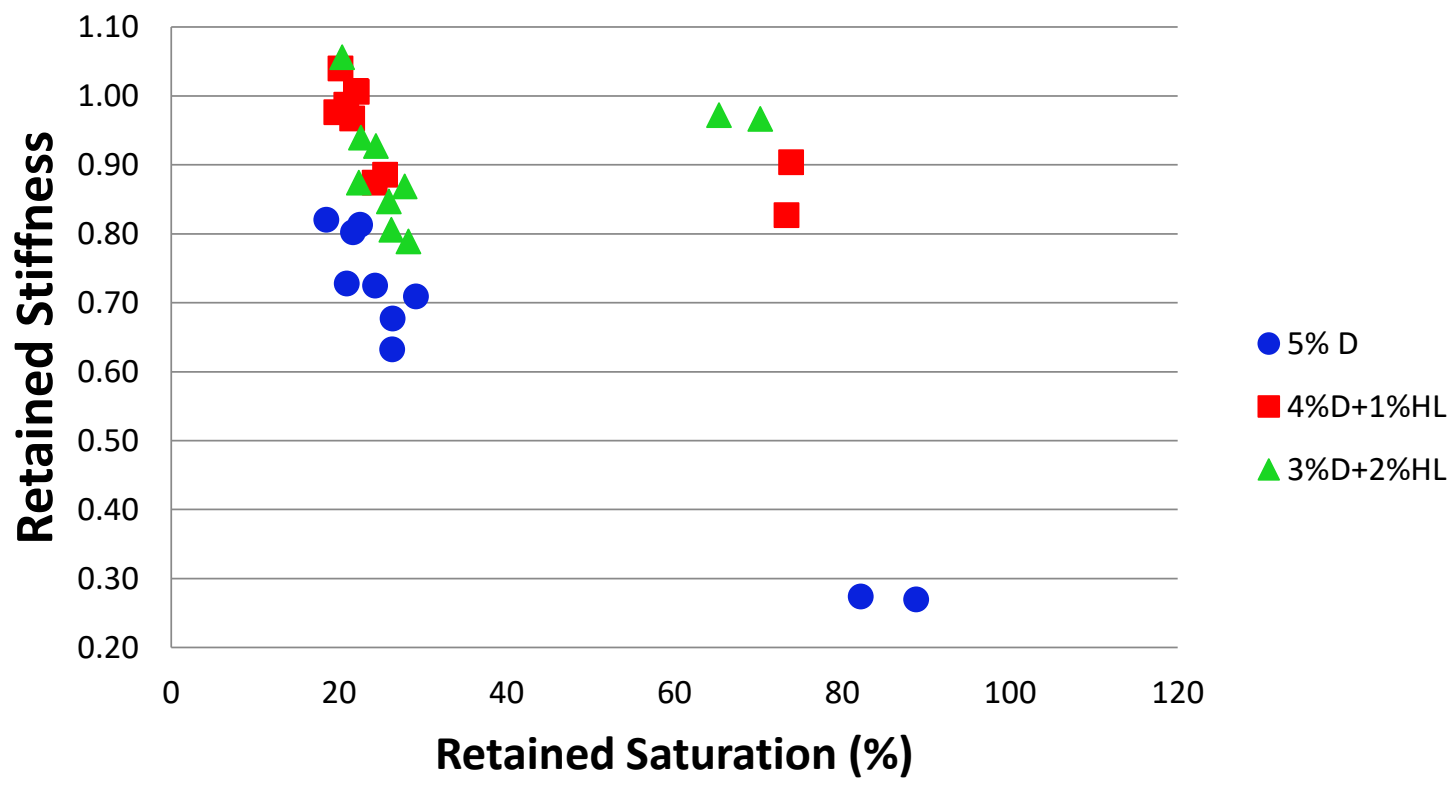

Figure 7: SATS test results for all combinations of aggregate D

The results of type D aggregate are presented in Figure 7. The effect of HL addition on moisture damage resistance is more apparent for type D aggregate. The retained stiffness for the combination having $0 \% \mathrm{HL}$ is between 0.7 and 0.8 but with the addition of $1 \%$ and $2 \% \mathrm{HL}$, the retained stiffness values are in a higher range of 0.9 to 1.0 . Again the mixture with $1 \% \mathrm{HL}$ 
gave the highest values but there is a very small difference noted between the moisture damage performance of 1 and $2 \% \mathrm{HL}$ in terms of retained stiffness against retained saturation.

Although there has been a positive effect of HL addition in most of the aggregate types used in this study, the difference is not very clear in the figures shown above (Figure 4 to Figure 7). To make an easy illustration of the effect of HL addition on mixtures made with different aggregate types and filler combinations, an average value has been calculated for the retained stiffness and retained saturation.

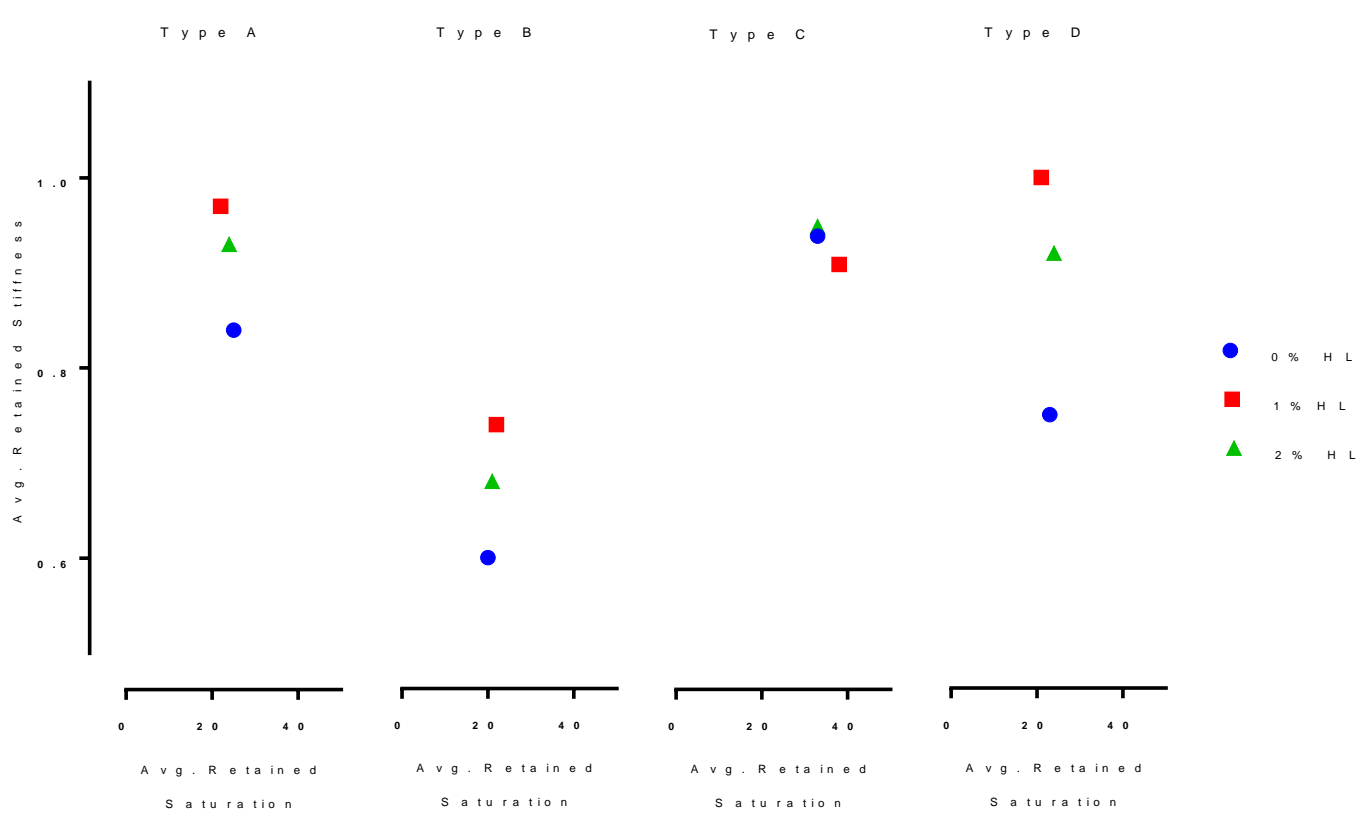

Figure 8: Behaviour of different aggregates with HL addition

As mentioned earlier, two runs for each combination have been undertaken which means for each combination 10 cores have been tested. As a general trend, the cores at position 1 and at position 5 have the highest retained saturation and hence the lowest retained stiffness compared to positions 2, 3 and 4 (Airey et al. 2005). So for the calculation of average value for each combination, a mean of retained stiffness and retained saturation has been taken for the cores at positions 2, 3 and 4 for both test runs. This average value of retained saturation against retained stiffness has been combined in Figure 8 for the asphalt mixtures consisting of four aggregate types used in this study.

It can be clearly seen in Figure 8 that there has been a definite effect of HL addition in most of the mixture types. In type A and B aggregates the addition of $1 \% \mathrm{HL}$ has increased the retained 
stiffness to about $15 \%$ and $23 \%$ respectively. With type D aggregate a noticeable increment of $33 \%$ has been calculated. Also in each case when HL addition seems to be beneficial, $1 \% \mathrm{HL}$ addition is slightly better than $2 \%$ HL addition. Based on these facts it can be concluded that the addition of $1 \% \mathrm{HL}$ gives better results compared to $2 \% \mathrm{HL}$ for the studied combinations.

\section{ITSM vs ITS in SATS test}

As per the SATS procedure discussed earlier, for each test run five cores are tested for stiffness (ITSM) before and after SATS conditioning. Retained stiffness is calculated by dividing the two stiffness values. In this particular study which looked at the beneficial effect of HL against moisture damage of asphalt mixtures, it has been found that HL improves moisture damage resistance in asphalt mixture for some aggregate types but the difference between the mixtures having HL and the mixtures without HL was not very distinctive. Various researchers have claimed that ITS results are better and more distinctive than ITSM as it is a more sensitive test in which the sample is loaded to failure (Jenkins 2000; Kim et al. 2007; Oke 2011). To check whether this statement is true for the SATS protocols or not, ITS tests were used instead of ITSM with type D aggregate combinations.

For these tests the retained strength, which is the ratio of conditioned to unconditioned cores, was calculated. As the ITS is a destructive test it is not possible to use for the same cores before and after conditioning as was the case when ITSM was used. To solve this problem, three unconditioned cores were tested with ITS and their mean value was calculated. After that, another set of cores were conditioned under the SATS protocol and tested with ITS and their retained strength was calculated for cores in each of the five positions in SATS apparatus by dividing the ITS value for that particular position by the mean ITS value of the unconditioned cores. 


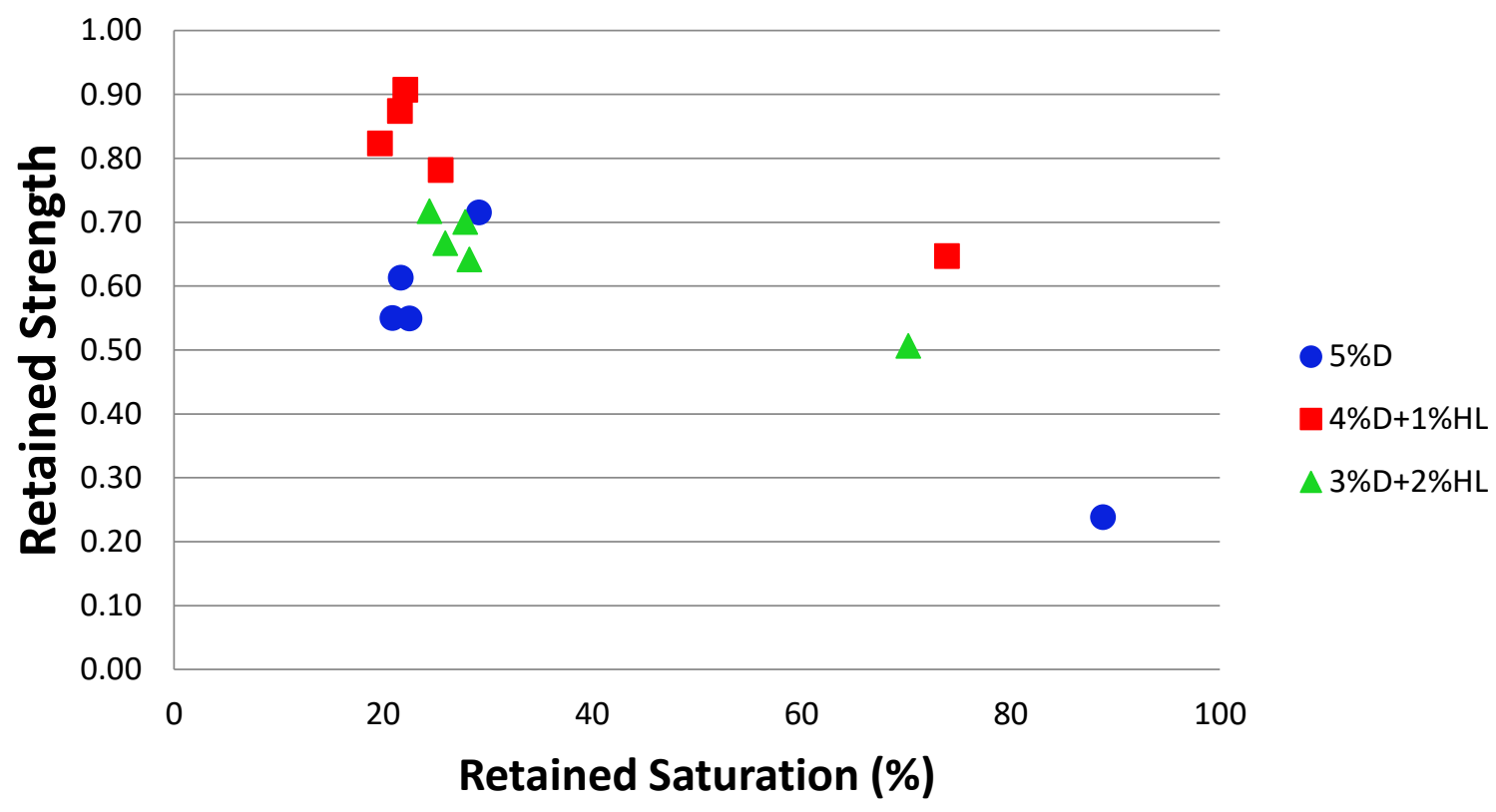

Figure 9: SATS test results for type D aggregates using ITS

Type D aggregate has been tested using the ITS test to get an idea of whether testing this way can give more distinctive results. Figure 9 shows the results of retained strength against retained saturation for the type D aggregate. If we carefully look at the results presented in Figure 9 and compare it with the original SATS test results presented in Figure 7, these look very similar to each other.

To get a clearer understanding a comparison has been made in Figure 10 between ITSM and ITS test results after SATS conditioning. A single value of retained stiffness or strength has been used by taking a mean value for each combination as discussed in section 5. In Figure 10 some differences can be observed among the results of the two test techniques, but the overall trend looks the same and even the relative difference between each combination for the two test techniques look similar. 


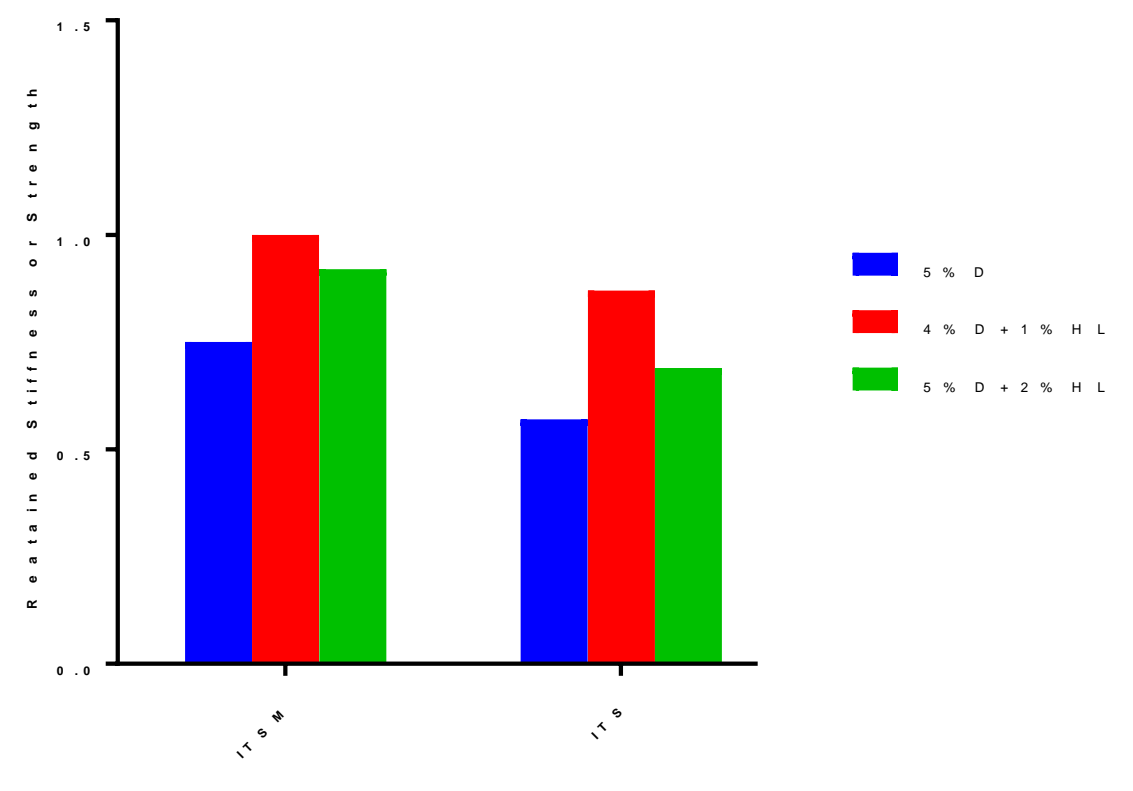

Figure 10: Comparison between ITSM and ITS after SATS conditioning

Based on the results shown in Figure 10 it can be concluded that ITS being destructive in nature may be more sensitive test than ITSM but after SATS conditioning ITSM is good enough as the retained strength calculated using ITS is very similar to that of the retained stiffness obtained in the ITSM.

\section{Discussion}

As discussed earlier, this study quantified the effect of hydrated lime on moisture susceptibility of asphalt mixture composed of different aggregates which vary significantly in mineralogy. For an inclusive characterization, it is very important to compare the results from SFE measurement with those of the asphalt mixture testing. This comparison has been made between SFE measurements $\mathrm{E}_{4}$ and retained stiffness from the SATS in Figure 11, for all the aggregate combinations. It is worth reiterating that type A and type D aggregates showed improvements with the use of HL and this is true for both the test techniques. Aggregates B didn't show any significant change in $\mathrm{E}_{4}$ with the use of HL but did show noticeable improvement in the retained stiffness. Aggregate C, on the other hand, does not show any noticeable change in either $\mathrm{E}_{4}$ or retained stiffness with the use of HL. 


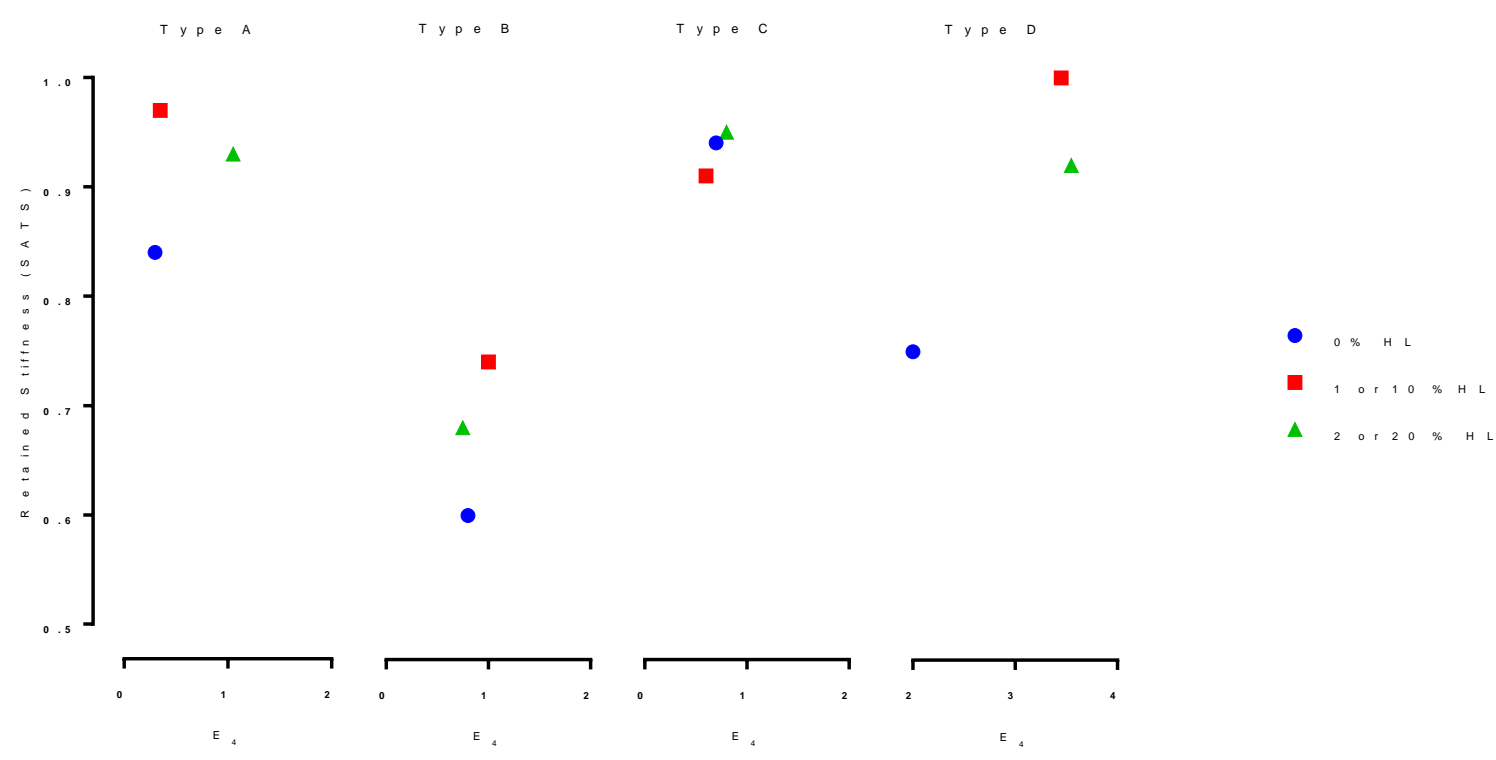

Figure 11: Comparison between SFE measurements $\mathrm{E}_{4}$ and retained stiffness in SATS

Based on the comparison made above it is concluded that the results of the two techniques are in line with each other for most of the aggregate types with aggregate type A and D showing good improvement with the use of HL. This is another thing worth noting that the dosage of HL giving better performance various among the types of aggregates. Aggregates A shows better results with $2 \%$ HL ( $2 \%$ in mixture and $20 \%$ in mastic) while aggregates type B and D show better results with1\% HL replacement.

There has been a considerable difference observed in the mineralogy of all four aggregates used in this study based on MLA results. Minerals such as albite, epidote, quartz and chlorite were found to be predominate in aggregates A and D. Aggregates type B was found to be abundant in calcite mineral while $\mathrm{C}$ type aggregate was found to be rich in chlorite and albite. The mineral which was most different from type A aggregate was calcite which was about $8 \%$. Another reason for the type $\mathrm{C}$ aggregate being different from type $\mathrm{A}$ was the low percentage of Quartz. Aggregate D was found to be predominate in Quartz mineral. It has been reported that rocks or aggregates which are composed of rich silica content are acidic in nature and those having high calcite are of a basic nature (Ward 1989). So type A and D aggregates can be referred to as acidic nature while type $\mathrm{B}$ and $\mathrm{C}$ can be classed as basic nature aggregates based on the above discussion. 
Different types of aggregates are used for the construction of asphalt pavements throughout the world. Aggregates may range from acidic to basic in nature depending on their source (Asphalt Institute 2007). Bitumen, on the other hand, is mostly acidic in nature so aggregates having a basic nature are expected to make a stronger bond with the acidic natured bitumen. That is the reason why moisture susceptibility of the asphalt mixture containing acidic aggregates has been found to be higher than in mixtures containing basic aggregates in many past studies (Airey et al. 2005; Airey et al. 2008; Grenfell et al. 2014; Khan et al. 2013; Nejad et al. 2013). However the results from this study are not in total agreement with this statement for the basic natured type B aggregates. In another study conducted by Grenfell et al. (2012), it was found that one granite type (acidic) aggregate was performing better than the basic limestone aggregate. So based on these facts it can be concluded that it is not always true that the moisture damage performance of basic aggregates will be better than acidic aggregates. Some acidic aggregates can give better moisture damage performance than basic aggregates and the performance can vary among different types of acidic aggregates depending on their mineralogical composition.

A significant improvement in moisture susceptibility of type A and type D aggregate combinations could be due to the fact that in the presence of HL, a water insoluble salt is produced when calcium ions accumulate on the surface of aggregates and react with the acid present in the bitumen. With the formulation of this water insoluble salt on the aggregate its surface roughness increases and this increased roughness helps in the formation of a stronger binder-aggregate interface (Blazek et al. 2000). In type B and C aggregates, there was no calcium ions cumulation due to their basic nature which is the reason why HL when used with type B and C aggregates didn't produce an additional beneficial effect that were observed with aggregates $A$ and D. This can be clearly seen in the results from the SATS test and SFE measurements for type $\mathrm{C}$ and in the SFE results for type $\mathrm{B}$. The improvement with the addition of HL for type B aggregate observed in the SATS results may be due to the fact that HL flocculates the clay particles present in type B aggregates and hence prevents them from building a water-displaceable barrier between bitumen and aggregate (Little 1995). To conclude it can be stated that the moisture damage mechanism is relatively complex and different aggregates can behave very differently when used in an asphalt mixture. 


\section{Conclusions}

In this paper moisture susceptibility assessment of asphalt mixture containing HL has been made through SFE measurements and the SATS test for four different aggregates sources having considerable difference in mineralogy. The following conclusions were reached based on the results presented in the paper.

- There has been a considerable difference observed in the mineralogy of all four aggregates used in this study based on MLA results. Minerals such as albite, epidote, quartz and chlorite were found to be predominate in aggregates A and D. Aggregate type $\mathrm{B}$ was found to be abundant in calcite mineral while $\mathrm{C}$ type aggregate was found to be rich in chlorite and albite. The difference in the behaviour of the four aggregate types to HL replacement can be credited in part to the mineralogical composition of the aggregates.

- Considering SFE measurements, a clear improvement in the moisture susceptibility was observed with the use of HL for type A and D aggregates. Type B and C aggregates, however, didn't show improvements in the presence of HL.

- In the SATS test, three out of four aggregates including types A, B and D showed improvement in the retained stiffness, but the performance of aggregate $\mathrm{C}$ remained unaffected by the use of HL. The performance of type C aggregate was already very good even without HL which is why this basalt aggregate didn't show any further improvement with the use of HL. The HL content of $1 \%$ was observed to be better than $2 \%$ in the three aggregates which showed improved performance with the use of HL.

- The trends obtained in the surface energy measurements were similar to the trends associated with the SATS test. The results clearly illustrate a close agreement between both techniques used in this study for the evaluation of moisture susceptibility.

- Many of the previous research studies state that the performance of the asphalt mixtures containing aggregates rich in calcite mineral were found to be better than those containing aggregate predominant in quartz. However, the results from this study are not in total agreement with this statement as they show that some aggregates rich in quartz can give better moisture damage performance than calcite aggregates and the performance can vary among different types depending on their mineralogical composition. 
- A comparison between ITSM (stiffness) and ITS (strength) tests after SATS conditioning was also undertaken as previous studies had indicated that ITS, being destructive in nature, gives more distinctive results. But the results of ITSM and ITS very found to be very similar to each other after SATS conditioning in terms of retained strength (using ITS) or retained stiffness (using ITSM).

\section{REFERENCES}

Adamson, A. W., and Gast, A. P. (1997). Physical Chemistry of Surfaces", 6th edition. New York: John Wiley and Sons, Inc.

Ahmad, N. (2011). "Asphalt mixture moisture sensitivity evaluation using surface energy parameters." University of Nottingham.

Airey, G. D., Choi, Y. K., Collop, A. C., Moore, A. J., and Elliott, R. C. (2005). "Combined laboratory ageing/moisture sensitivity assessment of high modulus base asphalt mixtures (with discussion)." Journal of the Association of Asphalt Paving Technologists, 74.

Airey, G. D., Collop, A. C., Zoorob, S. E., and Elliott, R. C. (2008). "The influence of aggregate, filler and bitumen on asphalt mixture moisture damage." Construction and Building Materials, 22(9), 2015-2024.

Bhasin, A. (2007). "Development of methods to quantify bitumen-aggregate adhesion and loss of adhesion due to water." Texas A\&M University.

BS 4987-1 (2005). "Coated macadam (asphalt concrete) for roads and other paved areas. Specification for constituent materials and for mixtures."

BS EN 12697-26 (2012). "Bituminous mixtures-Test methods for hot mix asphalt-Stiffness."

BS EN 13108-1 (2016). "Bituminous mixtures. Material specifications. Asphalt Concrete."

Caro, S., Masad, E., Bhasin, A., and Little, D. N. (2008). "Moisture susceptibility of asphalt mixtures, Part 1: mechanisms." International Journal of Pavement Engineering, 9(2), 81-98.

Collop, A., Choi, Y., Airey, G., and Elliott, R. (2004). "Development of the saturation ageing tensile stiffness (SATS) test." Proceedings of the ICE-Transport, 157(3), 163-171.

Grenfell, J., Ahmad, N., Airey, G., Collop, A., and Elliott, R. (2012). "Optimising the moisture durability SATS conditioning parameters for universal asphalt mixture application." International Journal of Pavement Engineering, 13(5), 433-450. 
Grenfell, J., Ahmad, N., Liu, Y., Apeagyei, A., Large, D., and Airey, G. (2014). "Assessing asphalt mixture moisture susceptibility through intrinsic adhesion, bitumen stripping and mechanical damage." Road Materials and Pavement Design, 15(1), 131-152.

Hicks, R., and Scholz, T. (2003). "Life Cycle Costs for Lime in Hot Mix Asphalt, 3 vol." Arlington (Virginia, USA): National Lime Association.

Hicks, R. G. (1991). Moisture damage in asphalt concrete, Transportation Research Board.

Howson, J., Masad, E., Little, D., and Kassem, E. (2012). "Relationship between bond energy and total work of fracture for asphalt binder-aggregate systems." Road Materials and Pavement Design, 13(sup1), 281-303.

Jenkins, K. J. (2000). "Mix design considerations for cold and half-warm bituminous mixes with emphasis of foamed bitumen." Stellenbosch: Stellenbosch University.

Kennedy, T. W. (1984). "Use of hydrated lime in asphalt paving mixtures." National Lime Association Bulletin 325. Arlington, VA: National Lime Association (NLA).

Kim, Y.-R., Lutif, J. S., Bhasin, A., and Little, D. N. (2008). "Evaluation of moisture damage mechanisms and effects of hydrated lime in asphalt mixtures through measurements of mixture component properties and performance testing." Journal of Materials in Civil Engineering, 20(10), 659-667.

Kim, Y., Lee, H. D., and Heitzman, M. (2007). "Validation of new mix design procedure for cold in-place recycling with foamed asphalt." Journal of materials in civil engineering, 19(11), 1000-1010.

Kim, Y. R. (, 2009). Modelling of Asphalt Concrete, McGraw-Hill Construction, ASCE Press USA.

Lesuesur (2010). "Hydrated lime: A proven additive for durable asphalt pavements - Critical literature review." Brussels: European Lime Association (EuLA), http://www.eula.eu

Little, D. N., and Bhasin, A. (2006). "Using surface energy measurements to select materials for asphalt pavement."

Little, D. N., and Petersen, J. C. (2005). "Unique effects of hydrated lime filler on the performance-related properties of asphalt cements: physical and chemical interactions revisited." Journal of Materials in Civil Engineering, 17(2), 207-218.

Liu, Y., Apeagyei, A., Ahmad, N., Grenfell, J., and Airey, G. (2013). "Examination of moisture sensitivity of aggregate-bitumen bonding strength using loose asphalt mixture and physico-chemical surface energy property tests." International Journal of Pavement Engineering, 1-14. 
Maldonaldo, R. "Bitumen modification with polyphosphoric acid." Proc., PROCEEDINGS OF THE 4TH EURASPHALT AND EUROBITUME CONGRESS HELD MAY 2008, COPENHAGEN, DENMARK.

Manual Series No. 24, M.-. (, 2007). "24 (MS-24),(2007) Moisture Sensitivity: Best Practices to Minimize Moisture Sensitivity in Asphalt Mixtures." Asphalt Institute, USA.

McCann, M., and Sebaaly, P. E. "Evaluating the performance of lime in hot mix asphalt mixtures." Proc., Airfield and Highway Pavement: Meeting Today's Challenges with Emerging Technologies, 614-624.

Mohammad, L. N., Saadeh, S., Kabir, M., Othman, A., and Cooper, S. (2008). "Mechanistic properties of hot-mix asphalt mixtures containing hydrated lime." Transportation Research Record: Journal of the Transportation Research Board, 2051(1), 49-63.

Oke, O. O. (2011). "A study on the development of guidelines for the production of bitumen emulsion stabilised RAPs for roads in the tropics." University of Nottingham.

Raynaud, C. (2009). "L’ajout de chaux hydratée dans les enrobés bitumineux." BTP Matériaux, $22,42-43$.

Sebaaly, P., Little, D., and Epps, J. (2006). "The benefits of hydrated lime in hot mix asphalt." Arlington (Virginia, USA): National Lime Association.

Voskuilen, J., and Verhoef, P. "Causes of premature ravelling failure in porous asphalt." Proc., Sixth international RILEM symposium on performance testing and evaluation of bituminous materials, 191-197. 